\title{
Factor structure of Bech's version of the Brief Psychiatric Rating Scale in Brazilian patients
}

\author{
J.A.S. Crippa ${ }^{1,2}$, \\ R.F. Sanches ${ }^{1}$, \\ J.E.C. Hallak ${ }^{1,3}$, \\ S.R. Loureiro ${ }^{1}$ and \\ A.W. Zuardi ${ }^{1}$
}

\author{
'Departamento de Neurologia, Psiquiatria e Psicologia M édica, \\ Faculdade de Medicina de Ribeirão Preto, Universidade de São Paulo, \\ Ribeirão Preto, SP, Brasil \\ ${ }^{2}$ Department of Psychological Medicine, Institute of Psychiatry, \\ University of London, London, UK \\ ${ }^{3}$ Department of Psychiatry and Behavioural Sciences, U niversity of M anchester, \\ Manchester, UK
}

\section{Correspondence \\ A.W. Zuardi \\ Departamento de Neurologia, \\ Psiquiatria e Psicologia Médica \\ FMRP, USP \\ Av. Bandeirantes, 3900 \\ 14049-900 Ribeirão Preto, SP \\ Brasil \\ Fax: 55-16-635-0713 \\ E-mail: awzuardi@ fmrp.usp.br \\ Research supported by FAPESP. \\ A.W. Zuardi is the recipient \\ of a CNPq fellowship. \\ J.A.S. Crippa was supported by \\ FAPESP (No. 99/11071-7 2000-2001) \\ and CNPq (No. 200984/01 2002- \\ 2003).}

Received February 25, 2002

Accepted July 26, 2002

\section{Abstract}

The objective of the present study was to evaluate the factor structure of Bech's version of the Brief Psychiatric Rating Scale (BPRS), translated into Portuguese. The BPRS was administered to a heterogeneous group of psychiatric inpatients $(\mathrm{N}=98)$ and outpatients $(\mathrm{N}=62)$ in a University Hospital. Each patient was evaluated from one to eight times. The interval between consecutive interviews was one week for the inpatients and one month for the outpatients. The results were submitted to factorial analysis. The internal consistency of the total scale and of each factor was also estimated. Factorial analysis followed by normalized orthogonal rotation (Varimax) yielded four factors: Withdrawal-Retardation, Thinking Disorder, Anxious-Depression and Activation. Internal consistency measured by Cronbach's $\alpha$ coefficient ranged from 0.766 to 0.879 . The data show that the factor structure of the present instrument is similar to that of the American version of the BPRS which contains 18 items, except for the absence of the fifth factor of the latter scale, Hostile-Suspiciousness.

\section{Key words}

- Brief Psychiatric Rating Scale

- Psychiatric status rating

scales

- Psychometrics

- Portuguese version

- Factorial analysis
The Brief Psychiatric Rating Scale (BPRS) developed by Overall and Gorham (1) is one of the most widely used scales in psychiatric research. Originally, the scale consisted of 16 items, but in 1966 two additional items (excitement and disorientation) were added to the American version, the BPRS-18 (2).

Factor analysis has shown that the items of the BPRS-18 can be grouped in clusters or factors, each one comprising a set of items that correlate highly among themselves, but associate little with the remaining items (3). Earlier studies identified four factors: Withdrawal-Retardation, Thinking Disorder, Anx-
ious-Depression and Hostile-Suspiciousness. Further analyses added a fifth factor, activation, containing the items mannerisms and posturing, tension and excitement (2). One of these studies, the Early Clinical Drug Evaluation Unit(ECDEU) manual, published by the United States National Institute of Mental Health, used several techniques for factor extraction (4). To improve reliability and comply with widely accepted standardization criteria, operational definitions or anchor points that allow discrimination of severity levels for each item of the BPRS have been introduced, resulting in modified ver- 
sions of the instrument (5-8). However, these new anchored versions of the BPRS have not been the subject of the extensive psychometric studies which have been applied to the standard BPRS (9).

Bech's version of the BPRS (5) has good reliability and validity indices, even when applied by raters with diverse clinical experience and using different methods (10-12). This version of the BPRS has been used in several studies involving different countries, languages and cultures (13-15). However, only one pilot study including 34 patients has been carried out to explore the factor structure of this instrument (12). For these reasons, the aim of the present study was to determine the factor structure of Bech's version of the BPRS, translated to Portuguese and adapted by Zuardi et al. (12), in a larger sample of subjects. The results obtained were compared to the ECDEU analysis of the American BPRS-18 (4). In addition, the internal consistency of the instrument was assessed by Cronbach's $\alpha$ coefficient.

The participants of this study were inpatients from the Psychiatric Unit $(\mathrm{N}=98)$ or outpatients $(\mathrm{N}=62)$ from the University Hospital of the Faculty of Medicine of Ribeirão Preto, SP, Brazil. A total of 160 patients (65 females and 95 males) aged $33.84 \pm 12.71$ years (mean \pm SD) participated. The patients were diagnosed according to ICD-10 (16) as having: schizophrenia $(\mathrm{N}=92)$, depressive disorder $(\mathrm{N}=21)$, bipolar affective disorder $(\mathrm{N}=19)$, schizoaffective disorder $(\mathrm{N}=14)$, acute and transient psychotic disorder $(\mathrm{N}=4)$, persistent delusional disorder $(\mathrm{N}=3)$, other specified mental disorders due to brain damage and dysfunction, and to physical disease $(\mathrm{N}=2)$, dementia in other specified diseases classified elsewhere $(\mathrm{N}=2)$, specific personality disorder $(\mathrm{N}=2)$, and dissociative (conversion) disorder $(\mathrm{N}=1)$. The educational level of the patients was not assessed. However, in a previous study, we have found that psychiatric patients attending this hospital usually have less than four years of education (17). The Research Ethics Committee of the University Hospital of Ribeirão Preto approved the study and the subjects and relatives responsible for the subjects signed a consent form after being informed of the research procedure.

The subjects were evaluated using the following instruments:

$B P R S$. The Bech and co-workers' (5) version of the BPRS, translated and adapted to Portuguese by Zuardi et al. (12), was used. In Bech's version of the BPRS, anchor points were added and severity options were reduced to five levels: $0=$ absent, $1=$ very mild or of doubtful presence, $2=$ present in mild degree, $3=$ present in moderate degree, $4=$ present in severe or extreme degree. The authors of this version think that for some symptoms, such as delusions, higher levels are inadequate (5). Some of the items of the BPRS were renamed by Bech and co-workers (5) in order to adjust to current psychopathological terms and to allow correlation with the Diagnostic and Statistical Manual of Mental Disorders (18; e.g., the item grandiosity became exaggerated selfesteem).

The Structured Interview Guide (SIG). The interviews were performed using a SIG, elaborated by Crippa et al. (11), that has been shown to enhance test-retest reliability for the total score and for individual items of the BPRS.

The raters - seven psychiatrists and one clinical psychologist - were trained in the use of the BPRS by two of the authors (J.A.S.C. and J.E.C.H.) as described by Crippa et al. (11). Two raters assessed the inpatients through a joint interview $(\mathrm{N}=46)$ or separately $(\mathrm{N}=52)$. After the interview, the BPRS was filled in independently by both raters, and placed in individual envelopes. Pairs were instructed not to share information about the tests until the end of the study. The first author (J.A.S.C.) experienced in the use of the BPRS took part in all the interviews. A single rater carried out the 
outpatients' ratings $(\mathrm{N}=62)$.

Inpatients were rated from 1 to 8 times at 1 -week intervals between consecutive ratings. Outpatients were rated once or twice. In the last case, the second interview was performed 1 month after the first one. In total, there were 361 filled in scales ( 76 for outpatients and 285 for inpatients). The intraclass correlation coefficient for the BPRS total score was 0.91 . The ratings made by the first author (J.A.S.C.), who was unaware of the diagnosis of the patients, were used for factorial analysis.

The scores from the 361 observations were submitted to factorial analysis followed by normalized orthogonal rotation (Vari$\max )$. The internal consistency for the global scale and for each of the factors obtained was calculated using Cronbach's $\alpha$ coefficient. The analysis was done with the statistical software package SPSS for Windows 6.0 .

Factorial analysis of the 18 items of the BPRS yielded four factors with eigenvalue above 1 . These factors were responsible for $68.1 \%$ of the variance. Seventeen items had their highest weight clearly allocated to one of those factors. Only item 8 (exaggerated self-esteem) had its highest weights distributed between the factors Activation and Thinking Disorder (0.56 and 0.42, respectively).

Table 1 compares the loadings of each BPRS item of the present study to that of the American BPRS-18 version (4). The same factors were allocated to 14 items in both studies. The ECDEU's Hostile-Suspiciousness factor was absent in this study and its three items were included in the Thinking Disorder factor (suspiciousness and hostility) and Withdrawal-Retardation factor (uncooperativeness). Also, the item exaggerated self-esteem was included in different factors in both studies.

The internal consistency for the whole scale, measured by Cronbach's $\alpha$ coefficient, was 0.653 . The coefficients for each
Table 1. Comparison of factor loads of the present version of the Brief Psychiatric Rating Scale (BPRS) with the American BPRS-18 version (ECDEU) (4).

\begin{tabular}{|c|c|c|}
\hline \multirow[t]{2}{*}{ Factors - Items } & \multicolumn{2}{|c|}{ Factor loadings } \\
\hline & This study & ECDEU (4) \\
\hline \multicolumn{3}{|l|}{ Anxious-Depression } \\
\hline 5. Self-depreciation and guilt feelings ${ }^{1}$ & 0.81 & 0.69 \\
\hline 2. Anxiety (psychic) ${ }^{2}$ & 0.81 & 0.75 \\
\hline 9. Depressive mood & 0.75 & 0.78 \\
\hline 1. Somatic concern & 0.61 & 0.63 \\
\hline \multicolumn{3}{|l|}{ Withdrawal-Retardation } \\
\hline 13. Psychomotor retardation 4 & 0.83 & 0.64 \\
\hline 16. Blunted or inappropriate affect ${ }^{5}$ & 0.82 & 0.79 \\
\hline 3. Emotional withdrawal & 0.80 & 0.81 \\
\hline 18. Disorientation and confusion 6 & 0.79 & 0.48 \\
\hline 14. Uncooperativeness & 0.79 & $(0.45)$ \\
\hline 7. Specific motor disturbances 5 & - & $(0.46)$ \\
\hline \multicolumn{3}{|l|}{ Thinking Disorder } \\
\hline 11. Suspiciousness & 0.81 & $(0.38)$ \\
\hline 15. Unusual thought content & 0.80 & 0.80 \\
\hline 12. Hallucinations ${ }^{8}$ & 0.78 & 0.71 \\
\hline 4. Conceptual disorganization & 0.71 & 0.64 \\
\hline 10. Hostility & 0.58 & - \\
\hline 8. Exaggerated self-esteem ${ }^{9}$ & $(0.42)$ & 0.54 \\
\hline \multicolumn{3}{|l|}{ Activation } \\
\hline 7. Specific motor disturbances ${ }^{7}$ & 0.90 & 0.57 \\
\hline 6. Anxiety (somatic) ${ }^{3}$ & 0.90 & 0.73 \\
\hline 17. Psychomotor agitation 10 & 0.82 & 0.74 \\
\hline 8. Exaggerated self-esteem 9 & 0.56 & - \\
\hline \multicolumn{3}{|l|}{ Hostile-Suspiciousness } \\
\hline 10. Hostility & - & 0.78 \\
\hline 11. Suspiciousness & - & 0.65 \\
\hline 14. Uncooperativeness & - & 0.64 \\
\hline 8. Exaggerated self-esteem 9 & - & $(0.44)$ \\
\hline
\end{tabular}

Note: The highest factor loading for each item is in bold type. Factor loadings in parentheses indicate loadings for items $>0.40$, but not included in the factor scoring. In the original BPRS-18: ${ }^{1}$ Guilt feelings, ${ }^{2}$ Anxiety, ${ }^{3}$ Tension, ${ }^{4}$ M otor retardation, ${ }^{5}$ Blunted affect, ${ }^{6}$ Disorientation, ${ }^{7}$ Mannerisms and posturing, ${ }^{8}$ Hallucinatory behavior, ${ }^{9} \mathrm{Grandi}-$ osity and ${ }^{10}$ Excitement.

Table 2. Intemal consistency for BPRS factors.

\begin{tabular}{lccc}
\hline Factor & Eigenvalue & \% of variance & Cronbach's $\alpha$ \\
\hline Factor 1 - Withdrawal-Retardation & 5.054 & 28.1 & 0.879 \\
Factor 2 - Thinking Disorder & 3.194 & 17.7 & 0.818 \\
Factor 3 - Activation & 2.476 & 13.8 & 0.877 \\
Factor 4 - Anxious-Depression & 1.534 & 8.5 & 0.766
\end{tabular}


factor are given in Table 2, which also shows the respective eigenvalues and the percentage of variance. The values of the $\alpha$ coefficient for each of the four factors were higher than that for the whole scale.

As can be seen from the data in Table 1, the factor structure of the present version of the BPRS (12) was similar to that of the American BPRS-18 version analyzed in the ECDEU (4). The main difference lies in the absence of the Hostile-Suspiciousness factor. The items which constituted this factor in the original scale were distributed between the factors Thinking Disorder (hostility and suspiciousness) and WithdrawalRetardation (uncooperativeness). Previous analysis using the BPRS-18 version (4) or other modified versions of the BPRS $(9,19)$ had already shown a high load of suspiciousness or hostility in the Thinking Disorder factor, as well as of uncooperativeness in the Withdrawal-Retardation factor. The last result was also obtained in the pilot study reported by Zuardi and co-workers (12).

The present data have shown a high internal consistency within each of the four factors of the scale, which is comparable to the results reported by Burger and co-workers (9). However, in their study, an additional factor (Hostile-Suspiciousness) was also identified, although with an $\alpha$ value of only 0.49 .

Such inconsistencies may be due to several circumstances, as for example the changes in the BPRS-18 introduced by Bech and co-workers (5), sample size and variation in psychopathological manifestations among patient samples. In the present study, the sample was heterogeneous regarding diagnosis, since it was representative of psychiatric patients attending a general hospital. In this respect, our results are not comparable to those obtained in studies with homogeneous patient samples.

The results of the present study show that, except for the absence of the HostileSuspiciousness factor, the factor structure of Bech's version of the BPRS translated to Portuguese (12) is similar to the BPRS-18 version analyzed in the ECDEU (4). In addition, the four-factor solution obtained in the current study agrees with the results obtained with the expanded version of the BPRS. There was general symptom dimension consistency in these studies for factors composed of positive (Thinking Disorder), negative (Withdrawal-Retardation), mania (Activation) and depression-anxiety symptoms (20).

\section{Acknowledgments}

We are grateful to Ms. Sandra Aparecida Bernardo for technical assistance and to Geraldo Cássio dos Reis for help in the statistical analysis. We also thank Paul Fallon for English corrections (Department of Psychiatry and Behavioural Sciences, University of Manchester, Manchester, UK) and Frederico G. Graeff (Department of Neuropsychiatry and Medical Psychology, University of São Paulo, Ribeirão Preto, SP, Brazil) for comments and suggestions on the manuscript.

\section{References}

1. Overall J E \& Gorham DR (1962). The Brief Psychiatric Rating Scale. Psychological Reports, 10: 799-812.

2. Hedlund J L \& Vieweg BM (1980). The Brief Psychiatric Rating Scale (BPRS). A comprehensive review. J ournal of Operational Psychiatry, 11: 48-65.

3. Czabor P \& Volovka J (1996). Dimensions of the Brief Psychiatric Rating Scale: An examination of the stability during haloperidol treatment. Comprehensive Psychiatry, 37: 205-215.

4. Guy W (1976). ECDEU Assessment Manual for Psychopharmacology (DHEW No. (ADM ) 76-338). National Institute of Mental Health, Rockville, MD, USA.
5. Bech P, Kastrup M \& Rafaelsen OJ (1986). Mini-compendium of rating scales for states of anxiety, depression, mania, and schizophrenia with corresponding DSMIII syndromes. Acta Psychiatrica Scandinavica, 326 (Suppl): 7-37.

6. Lukoff D, Liberman RP \& Nuechterlein $\mathrm{KH}$ (1986). Symptom monitoring in the reha- 
bilitation of schizophrenic patients. Schizophrenia Bulletin, 12: 578-602.

7. Gabbard GO, Coyne L, Kennedy LL, Beasley C, Deering CD, Schroder P, Larson J \& Cerney MS (1987). Inter-rater reliability in the use of the Brief Psychiatric Rating Scale. Bulletin of the Menninger Clinic, 51: 519-531.

8. Woerner MG, Manuzza $S$ \& Kane J M (1988). Anchoring the BPRS: an aid to improved reliability. Psychopharmacology Bulletin, 24: 112-117.

9. Burger GK, Calsyn RJ , Morse GA, Klinkenberg D \& Trusty ML (1997). Factor structure of the expanded Brief Psychiatric Rating Scale. J oumal of Clinical Psychology, 53: 451-454.

10. Andersen J , Larsen J K, Schultz V, Nielsen BM, Korner A, Behnke K, Munk-Andersen E, Butler B, Allerup P \& Bech P (1989). The Brief Psychiatric Rating Scale. Dimension of schizophrenia - reliability and construct validity. Psychopathology, 22: 168176.

11. Crippa J AS, Sanches RF, Hallak JEC, Loureiro SR \& Zuardi AW (2001). A structured interview guide increases Brief Psychiatric Rating Scale reliability in raters with low clinical experience. Acta Psychi- atrica Scandinavica, 103: 465-470.

12. Zuardi AW, Loureiro SR, Rodrigues CRC, Correa AJ \& Glock SS (1994). Estudo da estrutura fatorial, fidedignidade e validade da tradução e adaptação para o português da Escala de Avaliação Psiquiátrica Breve (BPRS) Modificada. Revista da Associação Brasileira de Psiquiatria - Asociacion Psiquiatrica de la America Latina, 16: 6368.

13. Baastrup PC, Alhfors UG, Bjerkenstedt $L$, Dencker SJ, Fensbo C, Gravem A, Pedersen V, Elgen K, Brekke B, FredslundAndersen $\mathrm{K}$, Lindholm $\mathrm{H}$, Lybeck $\mathrm{I}$, Morawski R, Nummi $K$, Silfverhjelm $H$, Vartiainen $\mathrm{H}$, Wiesel FA \& Aarvold $\mathrm{A}$ (1993). A controlled Nordic multicentre study of zuclopenthixol acetate in oil solution, haloperidol and zuclopenthixol in the treatment of acute psychosis. Acta Psychiatrica Scandinavica, 87: 48-58.

14. Ito M, Shiragata M, Kanno M, Mori $Y$, Hoshino K \& Niwa S (1998). Social cue perception in J apanese schizophrenic patients. Schizophrenia Research, 34: 113119.

15. Zuardi AW, Loureiro SR \& Rodrigues CRC (1995). Reliability, validity and factorial dimensions of the Interactive Observation
Scale for Psychiatric Inpatients. Acta Psychiatrica Scandinavica, 91: 247-251.

16. World Health Organization (1992). The ICD-10 Classification of Mental and Behavioral Disorders. WHO, Geneva, Switzerland.

17. Moreira MSS, Crippa J AS \& Zuardi AW (2002). Estudo longitudinal sobre a expectativa do desempenho social de pacientes psiquiátricos cuidados em uma enfermaria de hospital geral. Revista de Saúde Pública (in press).

18. American Psychiatric Association (1994). Diagnostic and Statistical Manual of Mental Disorders. 4th edn. Washington, DC, USA.

19. Dingemans PMAJ, Linszen $\mathrm{DH}$, Lenior ME \& Smeets RMW (1995). Component structure of the Brief Psychiatric Rating Scale (BPRS-E). Psychopharmacology, 122: 263-267.

20. Ventura J, Nuechterlein $K H$, Subotnik KL, Gutkind D \& Gilbert EA (2000). Symptom dimensions in recent-onset schizophrenia and mania: a principal components analysis of the 24-item Brief Psychiatric Rating Scale. Psychiatry Research, 97: 129-135. 